\title{
Dysregulated expression of cell surface glycoprotein CDCP1 in prostate cancer
}

\author{
Lifang Yang ${ }^{1,2}$, Sucharita M. Dutta ${ }^{1}$, Dean A. Troyer ${ }^{1,3}$, Jefferson B. Lin ${ }^{4}$, Raymond \\ A. Lance ${ }^{1,4}$, Julius O. Nyalwidhe ${ }^{1,2}$, Richard R Drake ${ }^{5}$, O. John Semmes ${ }^{1,2,3}$ \\ 1'Leroy T. Canoles Jr. Cancer Research Center, Eastern Virginia Medical School, Norfolk, VA, USA \\ ${ }^{2}$ Department of Microbiology and Molecular Cell Biology, Eastern Virginia Medical School, Norfolk, VA, USA \\ ${ }^{3}$ Department of Pathology and Anatomy, Eastern Virginia Medical School, Norfolk, VA, USA \\ ${ }^{4}$ Urology of Virginia, Norfolk, VA, USA \\ ${ }^{5}$ Department of Cell and Molecular Pharmacology and Experimental Therapeutics, Medical University of South Carolina, \\ Charleston, SC, USA
}

Correspondence to: John Semmes, e-mail: semmesoj@evms.edu

Keywords: glycoprotein, CUB-domain containing protein 1, prostate cancer, biomarker

Received: July 29, 2015

Accepted: October 06, 2015

Published: October 20, 2015

\section{ABSTRACT}

CUB-domain-containing protein 1 (CDCP1) is a trans-membrane protein regulator of cell adhesion with a potent pro-migratory function in tumors. Given that proteolytic cleavage of the ectodomain correlates with outside-in oncogenic signaling, we characterized glycosylation in the context of cellular processing and expression of CDCP1 in prostate cancer. We detected $135 \mathrm{kDa}$ full-length and proteolytic processed $70 \mathrm{kDa}$ species in a panel of PCa cell models. The relative expression of full-length CDCP1 correlated with the metastatic potential of syngeneic cell models and an increase in surface membrane expression of CDCP1 was observed in tumor compared to adjacent normal prostate tissues. We demonstrated that glycosylation of CDCP1 is a prerequisite for protein stability and plasma membrane localization, and that the expression level and extent of $\mathbf{N}$-glycosylation of CDCP1 correlated with metastatic status. Interestingly, complex $\mathbf{N}$-linked glycans with sialic acid chains were restricted to the $\mathrm{N}$-terminal half of the ectodomain and absent in the truncated species. Characterization of the extracellular expression of CDCP1 identified novel circulating forms and revealed that extracellular vesicles provide additional processing pathways. Employing immunoaffinity mass spectrometry, we detected elevated levels of circulating CDCP1 in patient urine with high-risk disease. Our results establish that differential glycosylation, cell surface presentation and extracellular expression of CDCP1 are hallmarks of PCa progression.

\section{INTRODUCTION}

Protein glycosylation is one of the most common and versatile post-translational modifications with a clear role in the regulation of numerous protein functions [1]. Altered glycosylation of cell surface proteins has been associated with cellular transformation and cancer progression underscoring a potential role in disease initiation and regulation [2-6]. We recently described a targeted approach for cell surface glycoprotein analysis and observed that CUB-domain-containing protein 1 (CDCP1) was over-expressed in metastatic prostate cancer [7].
$\mathrm{CDCP} 1$ is a type I single transmembrane protein also known as subtractive immunization associated $135 \mathrm{kDa}$ (SIMA135) [8], gp140 [9], transmembrane and associated with Src kinases (Trask) [10], and CD318 [11]. CDCP1 is expressed by stem or progenitor cells in hematopoietic, mesenchymal and neural tissues $[12,13]$ and is overexpressed in solid tumors including breast [14], colon [15], kidney [16], pancreatic [17], and lung [18]. Experimental data support a role for CDCP1 in cancer progression [19, 20], ECM degradation [21], anchorage-independent signaling [22], and cancer cell resistance to anoikis [19]. In PCa, the potential of CDCP1 as a therapeutic target has been reported [23, 24], but its 
expression and potential clinical significance have not been fully analyzed.

The existence of 14 consensus $\mathrm{N}$-glycosylation motifs and 3 proteolytic cleavage sites in the extracellular domain together with 5 tyrosine residues in the intracellular C-terminus reflects the functional role for CDCP1 in outside-in signal transduction. In fact, proteolytic cleavage of full-length CDCP1 results in a smaller "activated" protein, which is a substrate for Srcmediated tyrosine phosphorylation and a scaffold for the recruitment of $\mathrm{PKC} \delta[9,10,25]$. The two membranebound forms of CDCP1, the HMW-CDCP1 and a shorter LMW-CDCP1 species, have been observed in various cancer cells [9, 10, 19-21, 26] and keratinocytes [27]. The LMW-CDCP1 is generated from HMW-CDCP1 through the action of exogenous serine proteases via cleavage in the ectodomain at R368 and K369 [9, 10, 25]. In cancer cells, both forms of CDCP1 are tyrosine phosphorylated in the event of cell adhesion [22]. Although CDCP1 phosphorylation and proteolysis are well documented [28-32], the glycosylation status and its role in CDCP1 biology are not known.

In the present study, we characterized the glycosylation of CDCP1 in prostate derived cell lines using glycan-specific enzymes and glycosylation inhibitors. In addition, we evaluated the differential glycosylation and expression of CDCP1 between aggressive and nonaggressive prostate cancer cells and human tissues. We show that glycosylation determines protein stability, ectodomain processing and extracellular expression of CDCP1. We identified novel circulating extracellular forms of CDCP1 that displayed disease-specific expression in patient urine. Our findings suggest that glycosylation regulates the expression of extracellular forms of CDCP1 that correlate to disease state.

\section{RESULTS}

\section{Differential expression of CDCP1 in human prostate cancer cells}

Previous experimental data for CDCP1 in prostate cancer has been restricted to the study of PC3 and DU145 cancer models. In order to derive a broader consensus, we surveyed a panel of prostate cell lines for expression of CDCP1. As shown in Figure 1A, CDCP1 protein was detected in 19 of 20 prostate cell lines displaying variable expression of full-length $135 \mathrm{kDa}$ (HMW-CDCP1) and truncated $70 \mathrm{kDa}$ (LMW-CDCP1). PC3 lines displayed the highest staining for CDCP1 while PacMetUT1 showed only marginal expression. The normal prostatic cell line HPrEC, and immortalized RWPE-1 and PZ-HPV-7, expressed predominately HMW-CDCP1. In the PCa syngeneic models, the metastatic sublines displayed increased HMW-CDCP1 compared to the low metastatic counterparts (PC3-N2 vs
PC3-ML2, WPE-NB-26/65 vs RWPE-1, and ARCaPM vs ARCaPE). LNCaP cell lines with differing androgen responsiveness, showed static expression of CDCP1 with higher levels of LMW-CDCP1.

We extended the analysis of the ARCaP epithelial to mesenchymal transition (EMT) model to examine differential surface expression of CDCP1 related to the transition phenotype. Employing FACS analysis, we observed increased surface expression of CDCP1 in the mesenchymal-like ARCaPM compared to the epithelial-like ARCaPE cells (Figure 1B). This finding was visually confirmed with confocal microscopy showing that surface expression of CDCP1 was higher in ARCaPM (Figure 1C). These results suggest an association of CDCP1 surface expression with the metastatic potential of $\mathrm{PCa}$.

\section{CDCP1 expression in prostate cancer tissues}

We examined the expression of CDCP1 in frozen human prostate cancer tissues via immunofluorescence microscopy (Figure 2). Although CDCP1 was observed in both normal prostate epithelial and malignant cells, the staining intensity and subcellular localization were disparate. Human prostate cancer cells had a focally higher reactivity when compared to adjacent normal (Figure 2A, panels a-c). Malignant cells expressing CDCP1 protein belonged to a single acinus or to a few adjacent acini when compared to adjacent normal (Figure 2A, compare panels d-f to panels g-i). The tumor staining was predominantly localized to the plasma membrane (Figure 2B, d-f). The basal and apical surface demonstrated more concentrated CDCP1 than lateral membranes. In contrast, adjacent normal cells expressed CDCP1 in discrete juxtanuclear compartments, close to the basal side (Figure 2B, a-c) with dramatically reduced plasma membrane expression (Figure 2B, compare $\mathrm{c}$ to $\mathrm{f}$ ). The proportion of focally positive regions varied across malignant glands but was absent in all normal glands examined.

We examined a tissue microarray containing 100 human primary prostate cancer specimens for expression of CDCP1 in tumors compared with adjacent normal epithelial tissue (Supplemental Table S1 and Figure S1). The pronounced differential localization of CDCP1 observed in frozen sections was not observed in FFPE tissues. We observed variation in the intensity of CDCP1 expression and a reduction in the median staining intensity in tumor regions, consistent with an earlier report [24]. Other cell types including blood, endothelium, vascular smooth muscle, and prostatic stroma fibroblasts, were negative. In summary, although localization of CDCP1 is altered, the overall expression in prostate cancer tissues as performed on FFPE material is heterogeneous making CDCP1 a poor candidate as a tissue based biomarker. 


\section{Role of N-glycosylation on CDCP1 plasma membrane localization}

To establish the role of glycosylation in surface expression, we examined the sub-cellular localization of CDCP1 following inhibition of N-glycosylation. The PC3 sublines, PC3-N2 (low metastatic potential) and PC3-ML2 (high metastatic potential) were grown under subconfluent conditions in the presence $(+\mathrm{TM})$ or absence (-TM) tunicamycin. In figure $3 \mathrm{~A}$ we show strong cellular immunostaining for CDCP1 on both PC3 subtypes. However, treatment with TM resulted in significant changes in staining pattern with increased intensity in the cytoplasm.

The dependence of CDCP1 surface expression on $\mathrm{N}$-glycosylation was orthogonally confirmed via cell surface biotinylation. This approach preferentially labels the exposed primary amines of proteins on the surface of cells and exploits the strong interaction between biotin and streptavidin for the purification of cell-surface proteins. The purified surface proteins were separated by SDSPAGE and probed for expression of CDCP1. As shown in Figure 3B, the majority of HMW-CDCP1 and LMWCDCP1 was found in the cell surface biotinylated fraction (E) as opposed to the surface inaccessible fraction (FT). Upon TM treatment, the surface expression of HMWCDCP1 decreased concomitant with the appearance of an $80 \mathrm{kDa}$ protein. The observance of TM-dependent cytoplasmic expression of a degraded protein suggests an important role for $\mathrm{N}$-glycosylation in CDCP1 stability and turnover. In contrast, LMW-CDCP1 was resistant to TM treatment. These results support previous observations that LMW-CDCP1 derives from proteolysis of HMW-CDCP1 and is subject to slower turnover [25].

We also noted a differential sensitivity of HMWCDCP1 to TM treatment between N2 and ML2 cell lines. This was observed by comparing the TM-induced reduction inintensity of HMW-CDCP1 from the cell

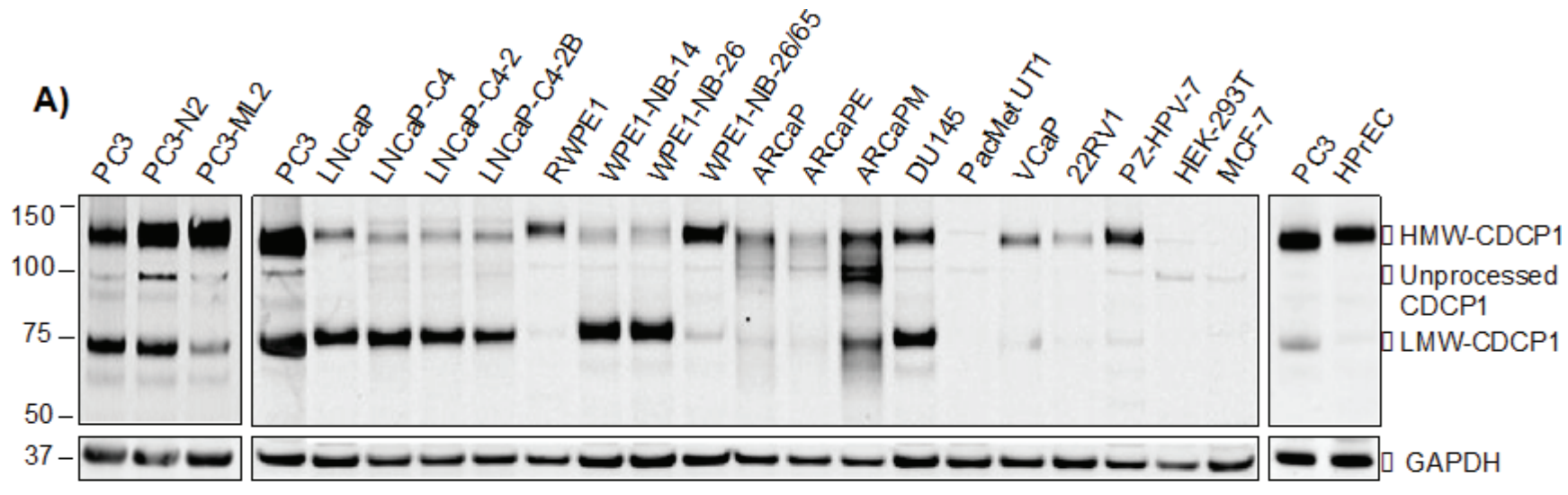

B)

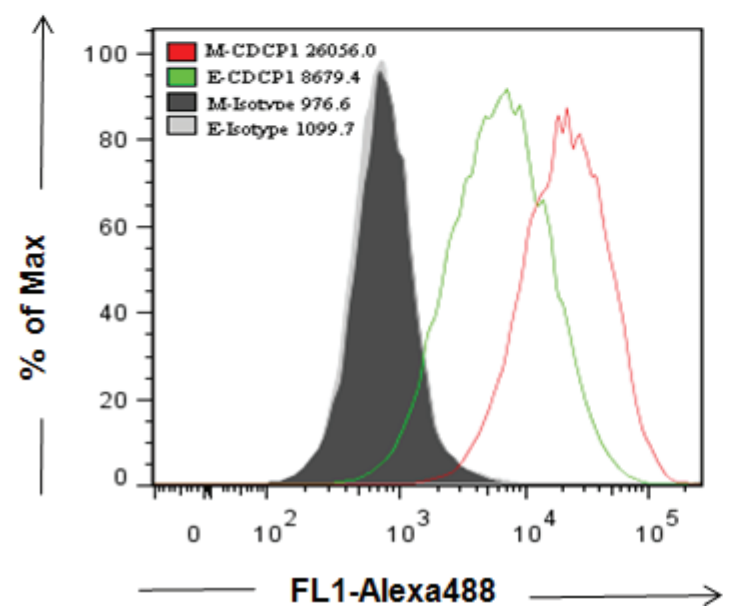

C)

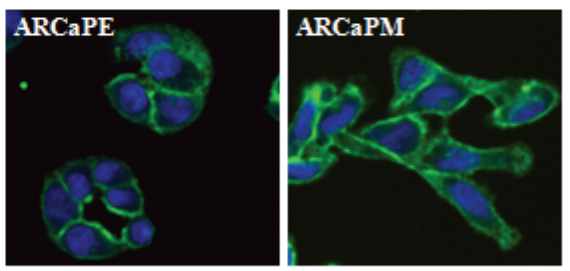

Figure 1: Expression of CDCP1 in human prostatic cell lines. (A) Expression of CDCP1 in human prostatic cell lines. Whole cell lysates were subjected to western blot analysis using anti-CDCP1 (CS4115). Extracts were normalized to total protein and expression of GAPDH used as a loading control. HEK-293T and MCF-7 cells served as negative controls. Surface expression of CDCP1 in ARCaP EMT model. Cell surface CDCP1 expression was detected by flow cytometric analysis (B) and immunofluorescence microscopy (C) using antiCDCP1 (AF2666). The nucleus was counterstained with TO-PRO3 (blue).In flow cytometric analysis, living cells, which are PI negative, were gated for analysis. The relative expression of $\mathrm{CDCP} 1$ in $\mathrm{ARCaPE}$ and $\mathrm{ARCaPM}$ cells was calculated by mean fluorescence intensity. 
lysates (Figure 3B, lanes 1 and 5) and isolated surface sialoglycoproteins (Figure 3B, lanes 4 and 8). In fact, HMW-CDCP1 from N2 cells displayed an $\mathrm{ID}_{50}$ of about $0.05 \mathrm{ug} / \mathrm{ml} \mathrm{TM}$ and a half-life of 3 hours (see Supplemental Figure S2). In contrast, HMW-CDCP1 in the ML2 cells displayed an approximately 4-fold higher $\mathrm{ID}_{50}$ and 3-fold increased half-life. These data demonstrate a structural difference in HMW-CDCP1 in N2 versus ML2 cell lines.

\section{Characterization of CDCP1 glycosylation}

Though known to be extensively glycosylated, the carbohydrate structure of CDCP1 has not been reported. We employed neuraminidase (hydrolyzes terminal sialic acid residues), endoglycosidase $\mathrm{H}$ (Endo $\mathrm{H}$, preferentially cleaves high mannose and hybrid oligosaccharides structures), and peptide-N-glycosidase F (PNGase F, cleaves asparagine-linked (N-linked) oligosaccharides) to determine the relative sensitivity of CDCP1 as a substrate for each enzyme. Treatment with PNGaseF produced a $90 \mathrm{kDa}$ and $53 \mathrm{kDa}$ band consistent with the predicted apparent mass of completely deglycosylated full-length and truncated CDCP1 (Figure 4A). Digestion with Endo $\mathrm{H}$ led to a mass shift of approximately $15 \mathrm{kDa}$ for HMW-CDCP1 (Figure 4B), indicating that a portion of the CDCP1 glycan is resistant. In contrast, Endo H treatment of LMW-CDCP1 produced several broad bands at or near the apparent molecular weight of completely deglycosylated LMW-CDCP1 (Figure 4, compare panels
4A and 4B). These results demonstrate that high-mannose or hybrid oligosaccharide chains contribute to a proportion of N-glycans present on CDCP1. Treatment with neuraminidase resulted in a decrease in HMW-CDCP1, whereas there was no detectable change in the LMW band (Figure 4C), indicating a higher sialic acid content in N-glycans of HMW-CDCP1 compared to LMW-CDCP1.

To assess the glycosylation status of CDCP1 in vivo, PC3 cells were treated with the N-linked glycosylation inhibitor tunicamycin (TM) or the mannosidase II inhibitor swainsonine (SW). Exposure to TM resulted in production of an $80 \mathrm{kDa}$ species that is smaller than completely deglycosylated CDCP1 (Figure 4D), suggesting that inhibition of glycosylation results in protein degradation. By comparison, LMW-CDCP1 was resistant to TM treatment. Treatment with SW decreased the mass of HMW-CDCP1, but had no obvious effect on LMW-CDCP1 (Figure 4E). This result suggests the addition of complex-type N-glycans to HMW-CDCP1 but not LMW-CDCP1, consistent with results obtained from treatment with Endo H. Taken together, these data suggest that the carbohydrate structures present on CDCP1 are high-mannose/hybrid-type N-linked glycans with complex $\mathrm{N}$-glycans terminated by sialic acid residues clustered in the N-terminal ectodomain region.

Having determined that sialylation is predominately confined to the ectodomain, we examined the sialylationstatus of HMW-CDCP1. PC3 cells were incubated with ManNAz to label sialic acid containing
A)
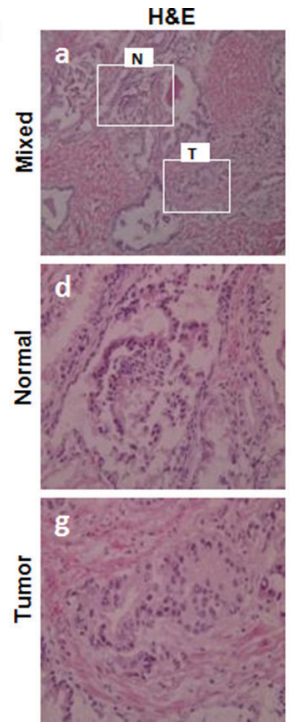

CDCP1+PI
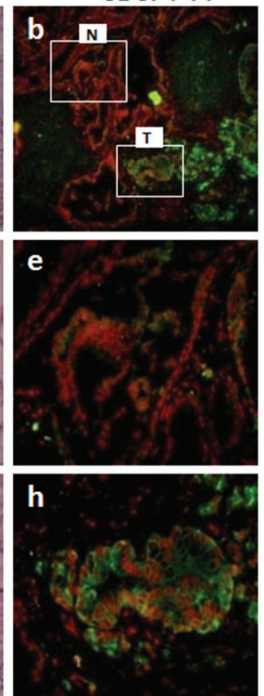

CDCP

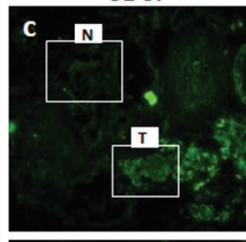

f
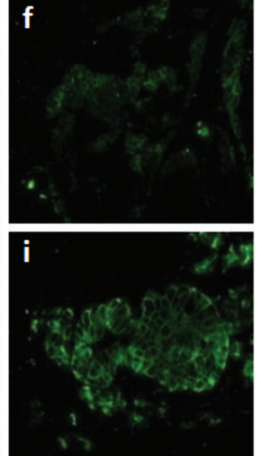

B)
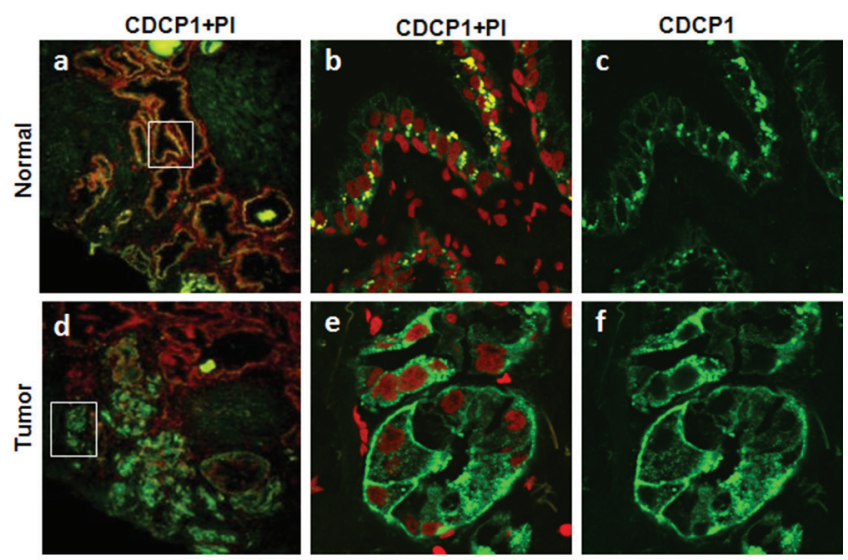

Figure 2: Expression of CDCP1 in prostate patient tissues. (A) Immunofluorescence microscopy of CDCP1 expression in matched normal $(\mathrm{N})$ and cancerous $(\mathrm{T})$ frozen prostate tissues from a prostate cancer patient (Gleason score $=4+3$ ). Frozen tissue sections $(6 \mu \mathrm{m})$ were stained with H\&E and a serial section analyzed with anti-CDCP1 (mAb41-2, green). Nuclei were counterstained with propidium iodide (red). Shown (panels a-c) are a lower magnification view (100X) of a region of tumor (T) and adjacent normal (N). High magnification (400X) of selected regions from normal (panels d-f) and tumor (panels g-i) glands correspond to the indicated areas marked in the top panels (white box). (B) Immunofluorescence analysis of CDCP1 subcellular localization. Frozen PCa sections were stained with anti-CDCP1 (mAb41-2, green) and the nuclei counterstained with propidium iodide (red). Representative images for normal (a-c) and tumor (d-e) glands are shown. High magnification of selected regions from normal $(b, c)$ and tumor (e, f) glands as indicated in the left panels (white box). Magnification 100X (a, d), 880X (b, c), 1040X (e, f). 
glycoproteins. As shown in Figure 4F, equal amounts of HMW-CDCP1 were immunoprecipitated from the PC3 sublines (although two-fold excess N2 to ML2 lysate was required). When probed for sialyl glycans using labeled streptavidin conjugate, the relative sialylation of HMW-CDCP1 was notably higher in the ML2 subline. To determine structural differences in sialylation, normalized amounts of CDCP1 were immunoprecipitated from cell lysates and subjected to lectin blotting using Sambucus nigra lectin (SNA, binds $\alpha 2,6$-linked sialic acid), Maackia amurensis lectin II (MALII, binds $\alpha 2,3$-linked sialic acid) or Wheat germ agglutinin (WGA, binds polysialic acid). The lectin affinity analysis indicated that sialylation via a2,6 linkage was observed in HMW-CDCP1 from both cells but the presence of $\alpha 2,3$ linkages and polysialic acid structures were preferentially expressed in HMW-CDCP1 of the ML2 subtype (Figure 4G). These results support that higher-order sialylation of CDCP1 is correlated with a metastatic phenotype in prostate cancer.

\section{Expression of extracellular CDCP1}

Cleavage of the HMW-CDCP1 at amino acid 368 results in the membrane-bound $70 \mathrm{kDa}$ LMW-CDCP1 and a $65 \mathrm{kDa}$ soluble form [25]. CDCP1 is also present in extracellular vesicles isolated from prostate cancer cell lines [23]. Thus, we examined the extracellular expression of CDCP1 as soluble and vesicle bound protein. We employed antibodies specific for either the extracellular or intracellular regions of CDCP1 (Figure 5A). The ectodomain specific antibody was raised against amino acids 33 to 333 and recognizes the $135 \mathrm{kDa} \mathrm{HMW}-\mathrm{CDCP} 1$ and the soluble $65 \mathrm{kDa}$ protein but not the $70 \mathrm{kDa}$ LMW-CDCP1. The intracellular specific antibody will recognize membranebound HMW-CDCP1 and LMW-CDCP1 but not soluble extracellular forms of CDCP1 cleaved from the membrane. When we examined serum-free condition medium (SFCM) for expression of CDCP1 using the ectodomain specific antibody we observed the HMW $135 \mathrm{kDa}$ species in PC3 and DU145 lines (Figure 5B). Interestingly, we observed $110 \mathrm{kDa}$ band in LNCaP, ARCaPE, ARCaPM and 22RV1. Analysis of DU145, the cell line in which the soluble $65 \mathrm{kDa}$ form was first described, yielded a prominent $65 \mathrm{kDa}$ band, HMW-CDCP1 and the novel $110 \mathrm{kDa}$ species. Note that the $65 \mathrm{kDa}$ species observed in DU145 was not the $70 \mathrm{kDa} \mathrm{LMW}$ species since the extracellular domain specific antibody will not recognize that protein.

We expanded our analysis of CDCP1 in DU145 to include fractionation of whole cell lysate, SFCM, extracellular vesicle cleared SFCM (SFCM-EVs), and extracellular vesicles (EVs). We then separated the proteins via SDS-PAGE and immunoblotted with extracellular-specific (upper panel) and intracellularspecific (lower panel) CDCP1 antibodies (Figure 5C). The DU145 whole cell lysate revealed a HMW 135 $\mathrm{kDa}$ species that was recognized by both antibodies, as expected. In addition, whole cell lysate expressed the $70 \mathrm{kDa}$ LMW-CDCP1 only recognized by the intracellular-specific antibody. Analysis of the SFCM revealed expression of the soluble $65 \mathrm{kDa} \mathrm{CDCP} 1$ as well as the $135 \mathrm{kDa} \mathrm{HMW}$ and $70 \mathrm{kDa}$ LMW forms. This is reflective of the SFCM containing vesicle-bound forms of CDCP1. When we examined the extracellular vesicular fraction, we observed an enrichment of the $135 \mathrm{kDa} H \mathrm{HMW}$ and $70 \mathrm{kDa}$ LMW forms as would be expected if the membrane bound forms of CDCP1 were processed into
A)

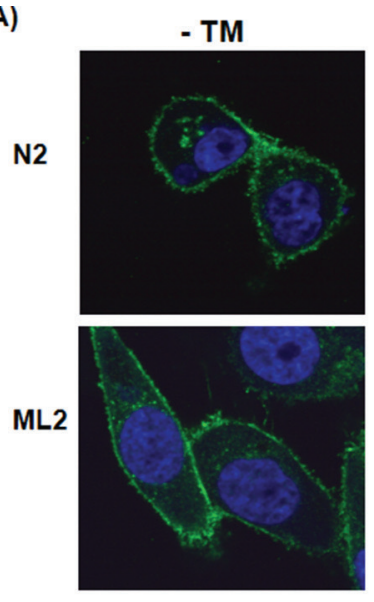

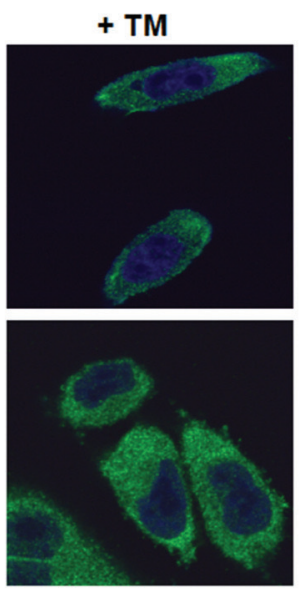

B)

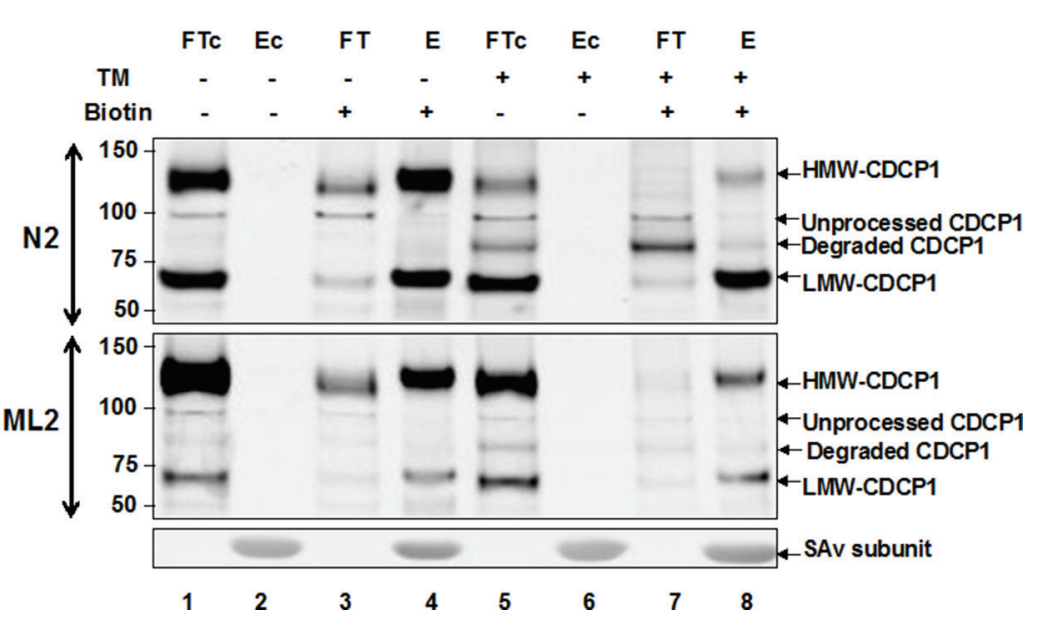

Figure 3: Surface expression of CDCP1 requires N-glycosylation. (A) PC3-N2 and PC3-ML2 cells were either treated with $1 \mu \mathrm{g} / \mathrm{ml}$ tunicamycin for $24 \mathrm{~h}(+\mathrm{TM})$ or untreated $(-\mathrm{TM})$. The cells were then fixed and subjected to immunofluorescence confocal microscopy using anti-CDCP1 antibody (CS4115, green). The nucleus was counterstained with TO-PRO3 (blue) and the images merged. (B) Protein extracts were prepared from PC3-N2 and ML2 cells that had been surface biotinylated (+) or untreated (-) and additionally grown in the presence $(+)$ or absence $(-)$ of tunicamycin. Biotinylated and nonbiotinylated protein fractions were separated by streptavidin affinity. The biotinylated bound (E) and unbound (FT) fractions, non-biotinylated bound (Ec) and unbound (FTc) fractions were separated by SDS-PAGE and immunoblotted with ant-CDCP1 (CS4115). 

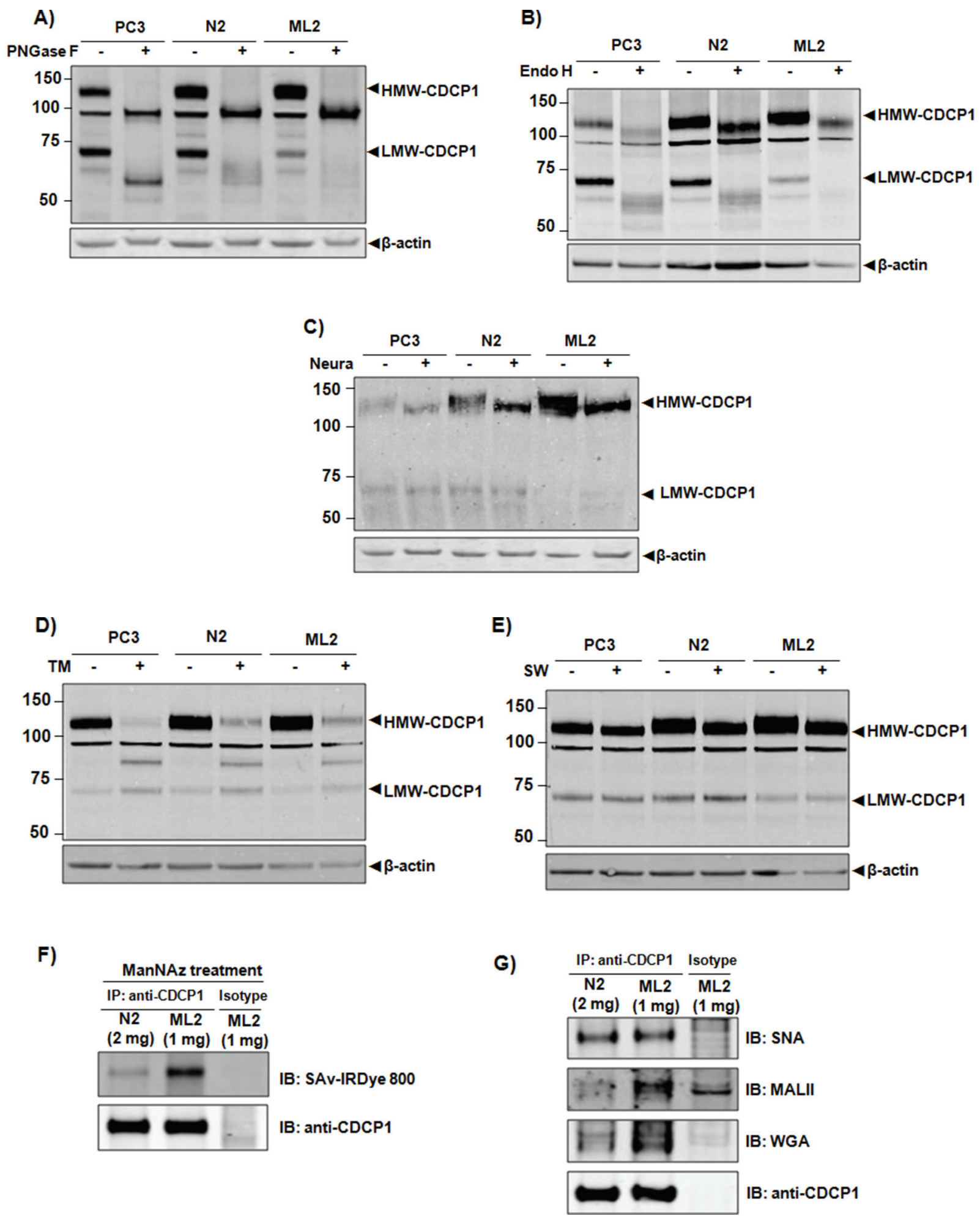

Figure 4: Characterization of CDCP1 glycosylation. In vitro deglycosylation of CDCP1 employing Neuraminidase (A) Endo H (B) and PNGase F (C). Hydrolyzed lysates from PC3, N2, and ML2 cells were separated on SDS-PAGE and immunoblotted with antiCDCP1 (CS4115). In vivo inhibition of glycosylation of CDCP1 in which PC3, N2, and ML2 cells were treated with tunicamycin (D) or swainsonine (E) in vivo for $24 \mathrm{~h}$. The total cell lysate was extracted, subjected to SDS-PAGE and immunoblotted with anti-CDCP1 (CS4115). $\beta$-actin was used as a loading control. Shown are HMW-CDCP1 and LMW-CDCP1. (F) Sialylation of HMW-CDCP1 protein was quantified by metabolically labeling sialyl proteins with ManNAz followed by immunoprecipitation of normalized amounts of CDCP1 with anti-CDCP1 (CS4115). A click reaction was performed to label the azido-sugar with biotin to allow for subsequent blotting with IRDye 800-conjugated streptavidin. (G) Normalized amounts of HMW-CDCP1 from N2 and ML2 cell was immunoprecipitated with anti-CDCP1 (CS4115) subjected to SDS-PAGE and immunoblotted with linkage-specific lectins SNA, MALII, and WGA as indicated. 
extracellular vesicles. We also observed an enrichment of the soluble $65 \mathrm{kDa}$ form in extracellular vesicles. Interestingly, we observed that the extracellular vesicular fraction was enriched for the novel $110 \mathrm{kDa}$ ectodomain form as well as a $25 \mathrm{kDa}$ membrane-bound cytoplasmic form of CDCP1. Cleavage of the HMW $135 \mathrm{kDa}$ protein at the extracellular interface would produce a $110 \mathrm{kDa}$ ectodomain and a $25 \mathrm{kDa}$ membrane bound protein. These data demonstrate that CDCP1 processing and activation are linked to microvesicle formation.

We employed FACS analysis to determine the membrane orientation of CDCP1 residing in extracellular vesicles. We bound microvesicles with latex beads to achieve a sufficient size for analysis on standard FACS instrumentation. A baseline performance was established by analysis of beads, beads plus microvesicles, and beads plus CD9 antibody (Figure 6A and 6B). When we examined extracellular vesicles isolated from ARCaP cells for expression of the exosome markers, CD9 and CD63, we observed specific expression and only marginal differences between ARCaPE and ARCaPM. However,

\section{A)}
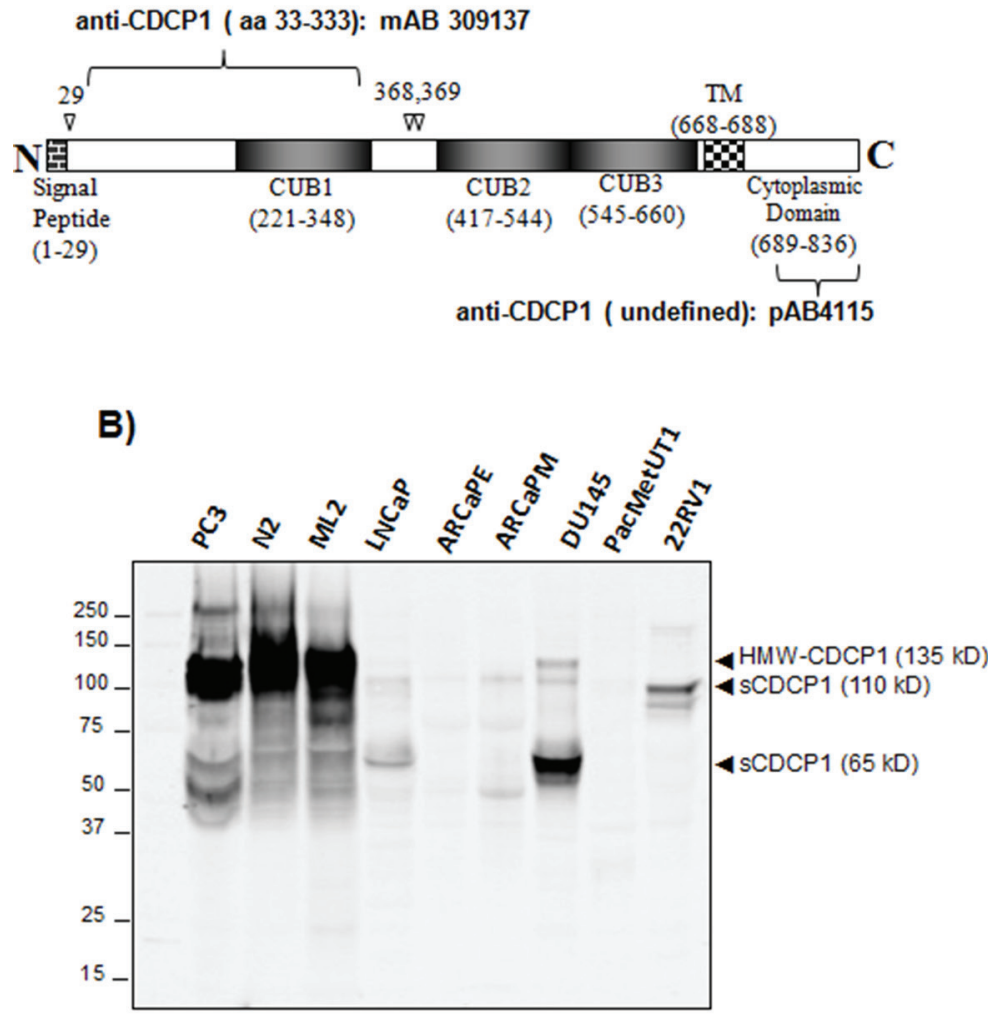

the expression of CDCP1 on extracellular vesicles derived from ARCaPM was over two-fold greater than that of ARCaPE (Figure 6C). Similar results were achieved with western blot analysis of the same sample (Supplemental Figure S3), indicating the expression of extracellular forms of CDCP1 is correlated to the metastatic potentials of PCa cells. We then assessed extracellular vesicles for CDCP1 expression using an antibody specific for the intracellular domain of CDCP1 (Figure 6D). Expression was only detected following membrane permeabilization and was most prominent in the ARCaPM cells. These results establish that CDCP1 in extracellular vesicles is expressed as a type I transmembrane protein and retains the differential phenotype observed for the corresponding "producer" cells.

\section{Extracellular CDCP1 is overexpressed in men with high-risk prostate cancer}

A number of integral cell surface proteins, such as c-Met, CD44 and EGFR are also produced as soluble

C)

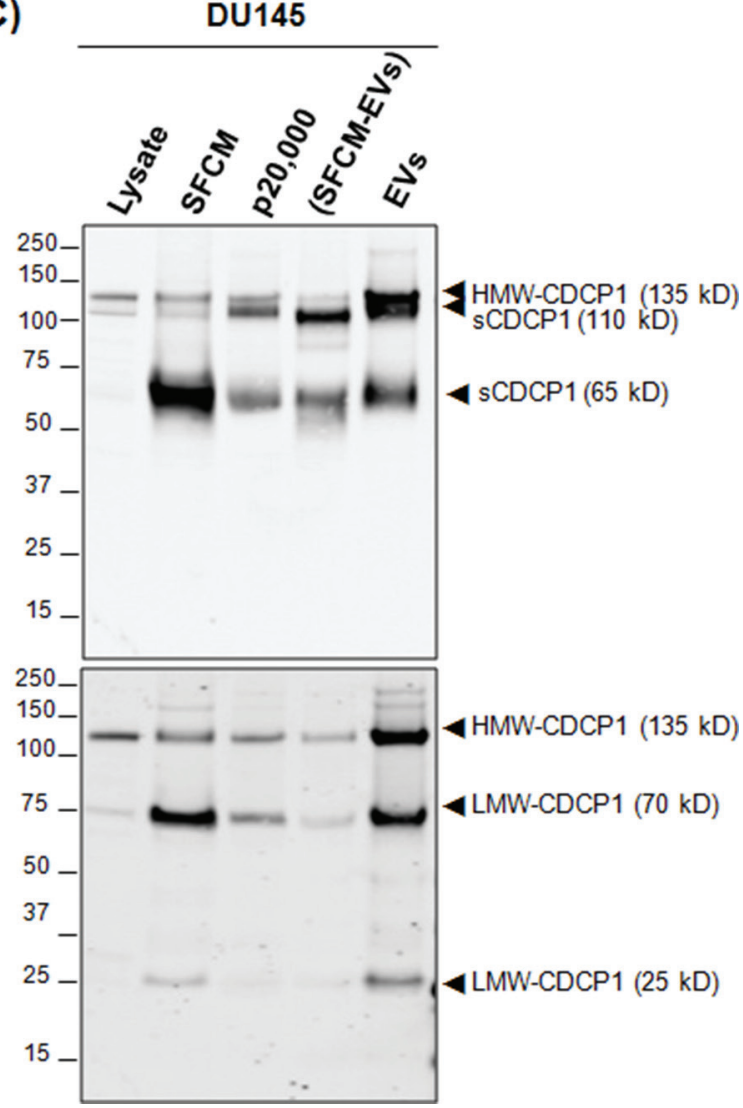

Figure 5: Analysis of extracellular forms of CDCP1. (A) A graphic representation of CDCP1 with important structural features noted. Shown is the cleavage site for processing of the membrane signal peptide (aa29) and extracellular processing of the ectodomain (aa368, 369). Antibodies targeting the extracellular domain and intracellular domain are indicated juxtaposed to the CDCP1 epitope. (B) Western analysis of indicated prostate cell lines with anti-CDCP1 (mAB309137) that only recognizes the extracellular ectodomain. HMWCDCP1 and soluble forms of CDCP1 are indicated. (C) Analysis of extracellular CDCP1 derived from DU145 prostate line. Whole cell lysates, serum-free conditioned medium (SFCM), supernatant following 20,000 g, SFCM depleted of extracellular vesicles (SFCM-EVs) and extracellular vesicle (EVs) fractions were analyzed as indicated. The same transfer filter was immunoblotted with anti-CDCP1 specific to the extracellular domain (mAB309137, upper panel) and to the intracellular domain (CS4115, lower panel). 


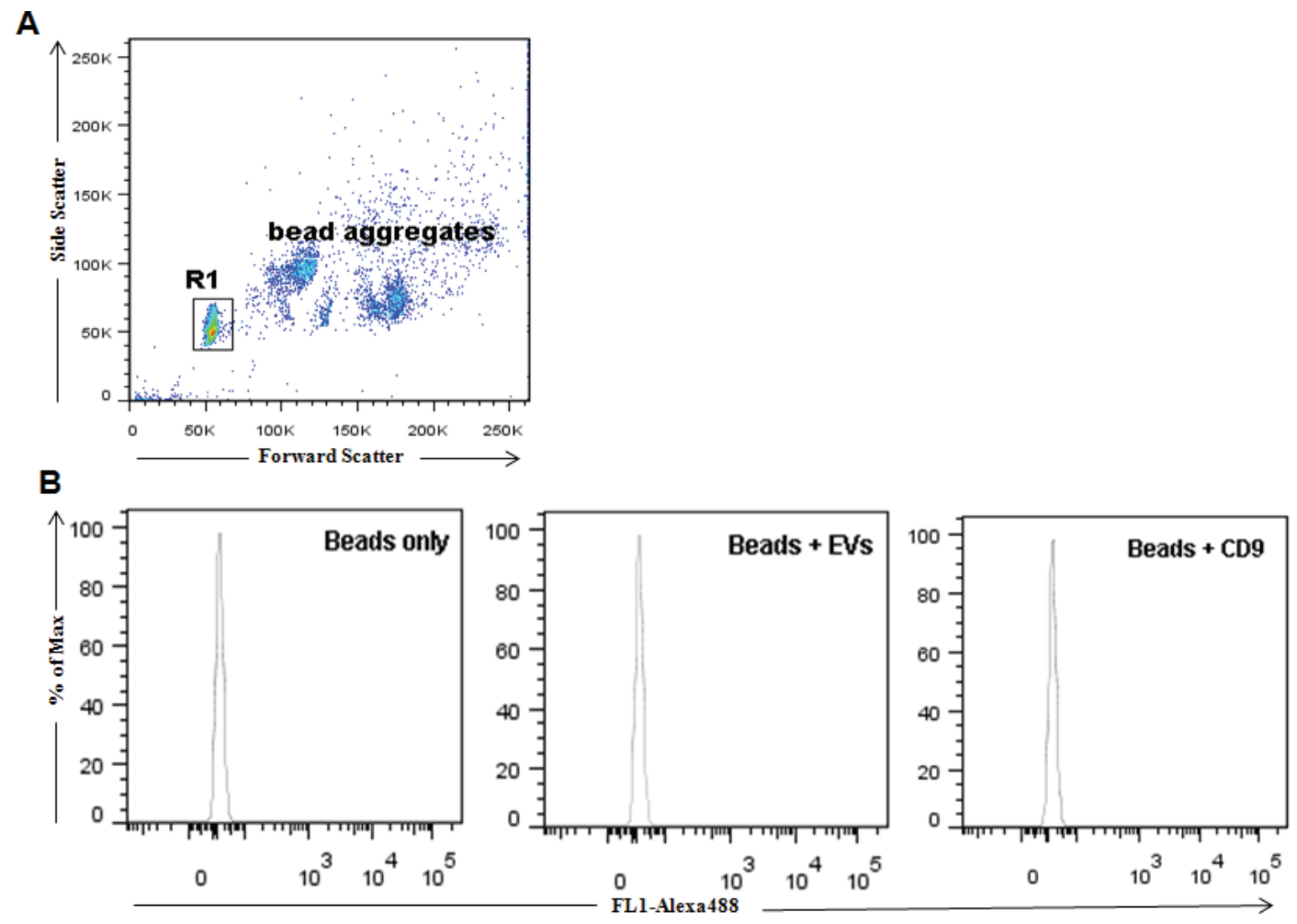

C
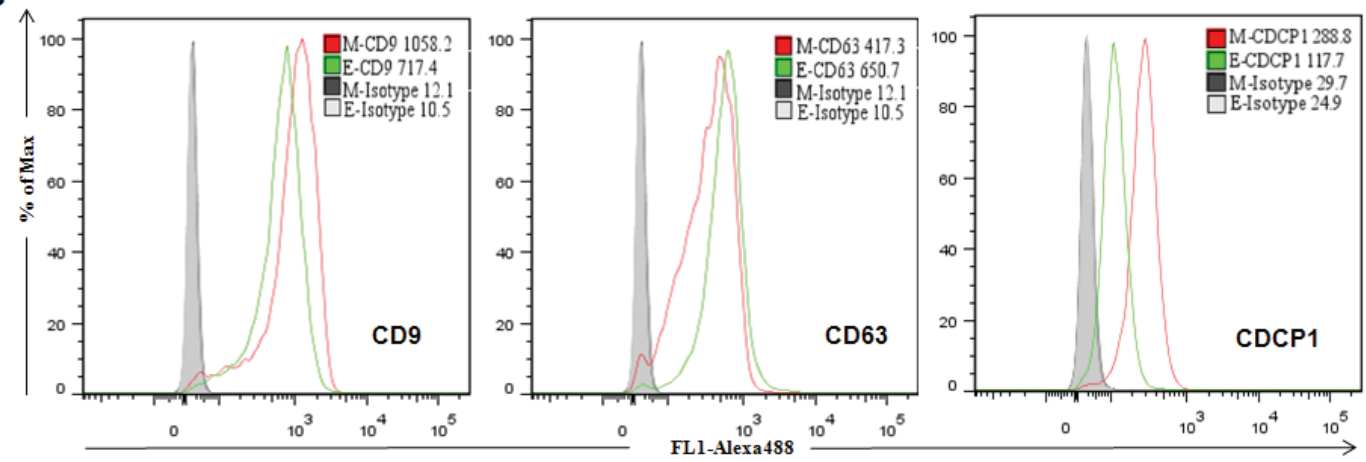

D

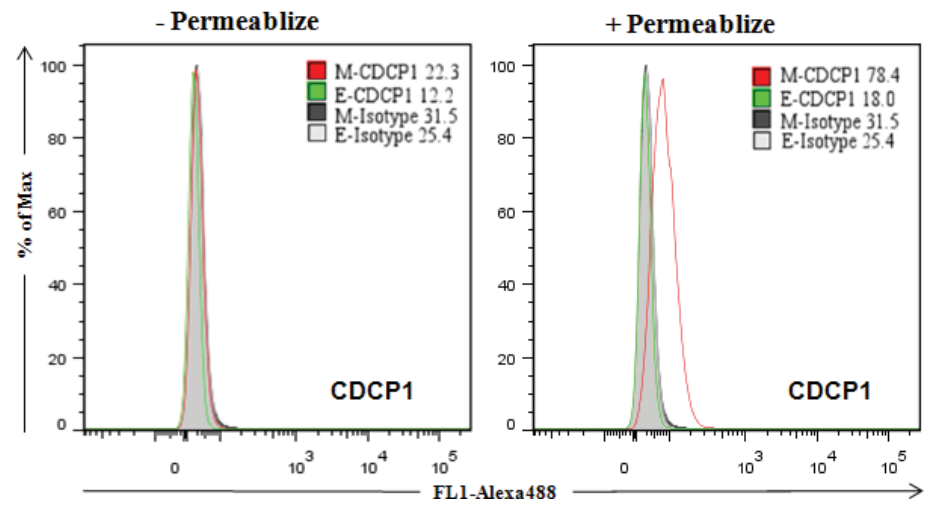

Figure 6: Flow cytometric analysis of surface protein expression on purified extracellular vesicles. EVs purified from cell cultures were coupled to the surface of latex beads and analyzed for the presence of CD9, CD63 and CDCP1. (A) Only bead singlets (R1) typically representing $70-80 \%$ of total beads were gated. (B) Analysis of latex beads alone, with EVs or with CD9 were used as controls to evaluate nonspecific binding. (C) Detection of surface expression of CD9, CD63 and CDCP1 by antibodies targeting to extracellular domains. The relative expression of ARCaPE (green) and ARCaPM (red) are shown with isotype control (shaded peak). (D) Detection of expression of CDCP1 by an antibody (CS4115) that targets the intracellular C-terminus. EVs were analyzed with and without permeabilization, as indicated. 
molecules with potential diagnostic utility [33-35]. We utilized antibodies specific for the CDCP1 ectodomain to analyze patient-derived urine. As shown in Figure 7A, analysis of urine samples with antibody targeted to the ectodomain detected several CDCP1 species with apparent molecular weights ranging from $110 \mathrm{kD}$ to $25 \mathrm{kD}$. This is the first report of circulating CDCP1 detected in prostate cancer patients.

Having determined that an extracellular form of CDCP1 can be detected in urine, we established an immuno-MS workflow for quantitative detection of CDCP1 (Figure 7B). For this purpose we used the ectodomaintargeted antibody to immunoprecipitate CDCP1 directly from urine-EPS. Due to the low abundance of CDCP1, we pooled and concentrated samples from high-risk and low-risk prostate cancer patients. We then performed immunoprecipitation on normalized pooled samples as described. The immunoprecipitate was subsequently fractionated by SDS-PAGE and individual gel regions excised and subjected to LC-MS/MS analysis. We detected CDCP1 isoforms from gel bands suggesting multiple forms ranging from $45-85 \mathrm{kDa}$ derived from low-risk and highrisk pools (Figure 7C and 7D). We did not detect CDCP1 following immunoprecipitation with antibody isotypes controls (data not shown).

We next performed label free quantitation of the immunoprecipitated CDCP1 in each patient risk group by precursor ion quantitation. This method sums all detected CDCP1 ions for a higher degree of confidence in the quantitative analysis. We observed that CDCP1 was present at significantly higher levels in the high-risk compared to low-risk patients (Figure 7E). These data indicate that extracellular forms of CDCP1, detectable in clinical fluids, have the potential to discriminate between prostate cancer risk groups.

\section{DISCUSSION}

CDCP1 has emerged as an important tumorregulating membrane bound protein. Although the mechanism of action of CDCP1 in facilitation of metastasis still avoids a consensus, blocking the proteolytic release of soluble ectodomains and coincident formation of the $70 \mathrm{kDa}$ membrane-bound fragment inhibits early metastatic events [30]. Thus, the posttranslational processing of CDCP1 appears to play an integral role in the regulation of this important protein. So, we postulated that differential glycosylation, perhaps via altered proteolysis, regulates CDCP1 expression and its role in cancer progression. Our current results support this hypothesis in several aspects. First, we demonstrated that CDCP1 glycosylation is extensive and variable comprised of complex type N-glycans and sialic acid, providing structural diversity needed for regulation of function. Second, inhibition of N-linked glycosylation altered the relative expression of HMW and LMW forms of CDCP1, induced the expression of degraded species and prevented cell surface presentation. Thus, N-glycosylation of CDCP1 impacts proteolytic processing and subcellular localization of CDCP1, which in turn contributes to protein expression and stability. Furthermore, we uncovered differential glycan structure of HMW-CDCP1 between "normal" and "metastatic" cellular phenotypes. Therefore, we postulate that the glycosylation of CDCP1 serves as an extracellular signal, together with intracellular phosphorylation, that modulates cell adhesion, anchorage-independent growth and metastasis.

Functionally, CDCP1 likely provides a basal activity that enforces anchorage-dependent growth since ablation of CDCP1 expression promotes tumor metastasis [36,37]. However, in model systems in which CDCP1 expression is dysregulated it provides clear tumor promoter activities [17-21, 28, 30, 31]. The "switch" in this process appears to be extracellular cleavage of CDCP1 allowing for Src-mediated signaling [10] and direct interaction with integrin [31] to drive migration and invasion. Thus, CDCP1 displays a profound structural/functional shift concomitant with tumor progression. There is precedence that compartmentalization of CDCP1 can regulate this functional shift. Specifically, CDCP1 localization to membrane lipid rafts was shown to be a prerequisite to invadopodia-mediated cell invasion [17], and cell migration in an ovarion cancer model required EGFinduced relocalization of CDCP1 to the cell surface [38]. We propose that glycosylation of CDCP1 dictates cell surface presentation and proteolytic processing to drive the functional switch between tumor suppressor and tumor promoter activities.

In light of its role in cancer progression, CDCP1 tissue expression has been examined as a potential cancer biomarker with conflicting results. For instance, increased CDCP1 expression correlated with poor prognosis in lung and colorectal [39, 40] but better outcomes in esophageal cancer [41]. In our study, we evaluated CDCP1 expression in both frozen and FFPE tissues. Although examination of CDCP1 expression in frozen prostate tissues by immunofluorescence microscopy revealed significant differences in subcelluar distribution between cancer and adjacent normal, these results were not recapitulated in our survey of FFPE tissue. In FFPE tissues, the expression pattern in cancerous and normal glands was heterogeneous, likely the result of antigen structural changes during FFPE tissue processing. Our assessment of CDCP1 expression in an FFPE tissue array demonstrated a modest decrease in tumor compared to normal, consistent with an earlier report [24]. Given current affinity reagents, CDCP1 expression in FFPE tissues does not appear to provide diagnostic value for prostate cancer.

The proteolytic cleavage of the CDCP1 extodomain yields a soluble $65 \mathrm{kDa}$ extracellular polypeptide when examined in DU145 cells $[8,25]$. In the present 
A)

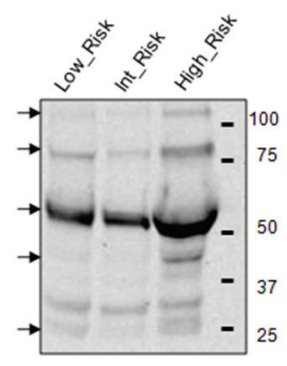

B)

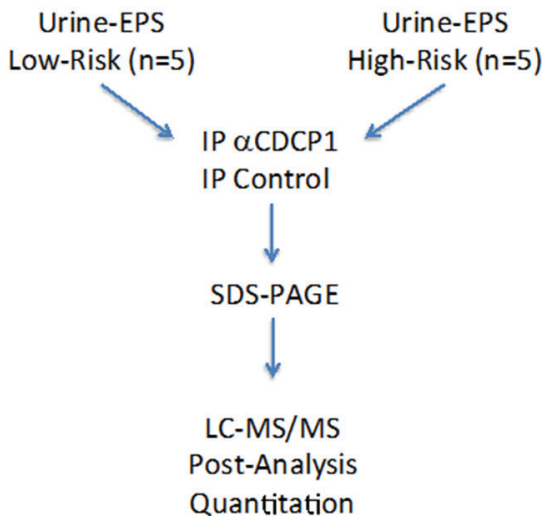

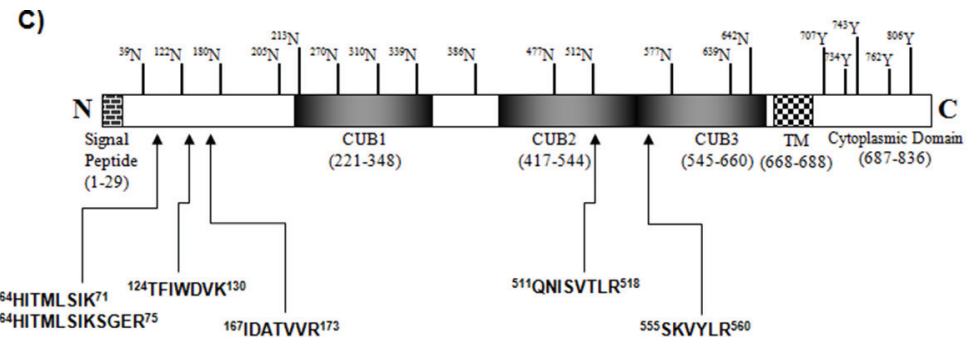

D)

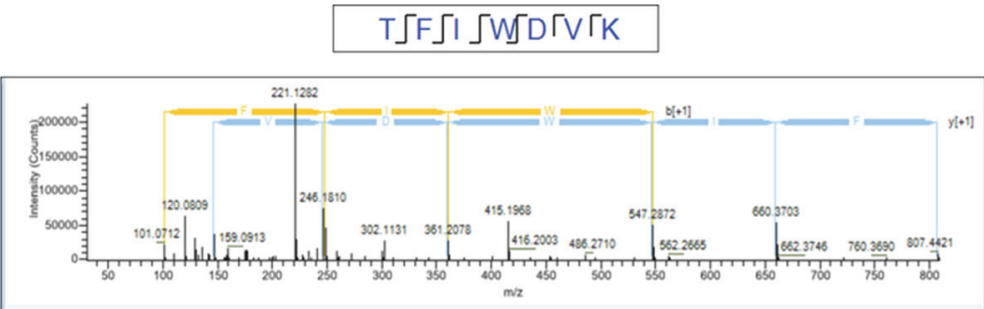

E)
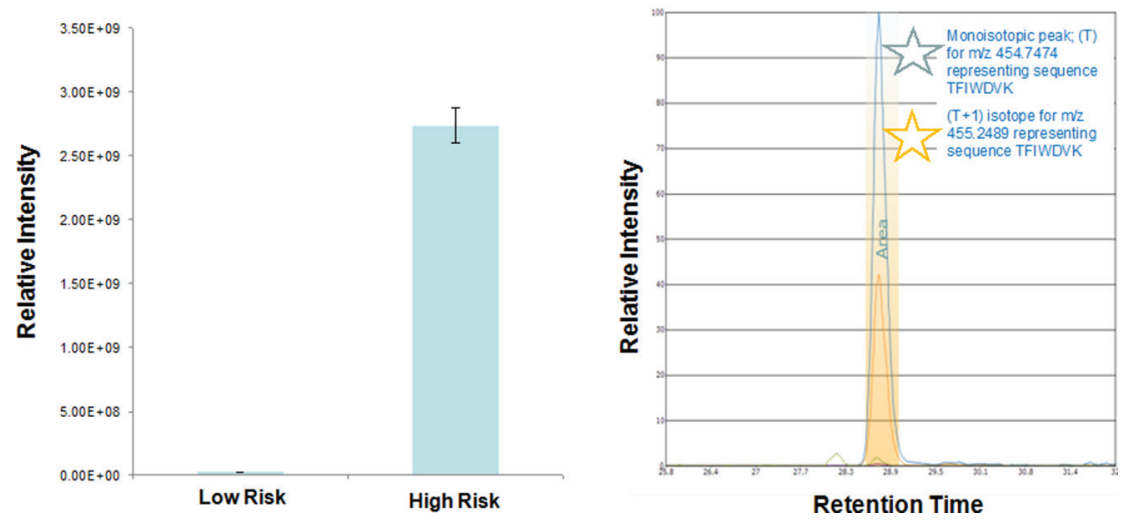

Figure 7: Quantitation of extracellular CDCP1 between high- and low-risk prostate cancer. (A) Detection of CDCP1 in urine-EPS samples. Western blot analysis of urine-EPS samples from low-risk, intermediate-risk, and high-risk PCa were performed with a goat antibody against the extracellular domain (aa 33-666) of CDCP1 (AF2666). (B) Scheme for immune-enriched quantitative mass spectrometry analysis of CDCP1 proteins from urine-EPS. CDCP1 was immunoprecipitated with anti-CDCP1 (AF2666) from urine-EPS as described. Goat IgG was included as an isotype control. Eluents of the purified CDCP1 proteins were subjected to SDS-PAGE. Gel bands were cut into 15 equally spaced pieces $(25-150 \mathrm{kDa}$ ) and subjected to LC-MS/MS analysis. (C) Identification of peptides spanning extracellular domains of CDCP1 detected by LC-MS/MS. (D) Representative MS/MS spectrum of tryptic peptide TFIWDVK of sCDCP1 digestion. (E) Quantitative precursor MS results display simultaneous identification and quantitation results for the 6 unique peptides from CDCP1. The left panel shows the relative peak area differences for the combined targeted peptides. The right panel shows the extracted ion chromatogram and integrated peak area of primary ions per targeted peptide. 
study we analyzed both soluble and vesicle-associated extracellular species of CDCP1. We identified membrane bound HMW/LMW forms of CDCP1 and demonstrated that a Type I transmembrane orientation is recapitulated in extracellular vesicles produced by PCa cells. In addition, we observed a $65 \mathrm{kDa}$ and novel $110 \mathrm{kDa}$ soluble form that was enriched in serum free culture medium depleted of microvesicles. A novel membrane-bound $25 \mathrm{kDa}$ species containing the cytoplasmic domain was observed enriched in extracellular microvesicles. The presence of a $110 \mathrm{kDa}$ extracellular protein and a $25 \mathrm{kDa}$ intracellular protein suggested an additional site of proteolytic cleavage of the CDCP1 ectodomain proximal to the extracellular membrane border. Our study provides evidence of novel processing ofextracellular CDCP1 that results in both soluble and vesicle-associated species.

Immunoprecipitation of CDCP1 followed by sensitive mass spectrometry, was able to confirm the existence of extracellular forms of CDCP1 in urine of $\mathrm{PCa}$ patients. Moreover, using quantitative mass spectrometry we demonstrated that increased levels of CDCP1 correlated with aggressive disease. Although followup analysis with improved assay sensitivity allowing for analysis of individual samples is needed, the results suggest that extracellular species of CDCP1 may serve to discriminate aggressive from indolent disease.

In summary, our data reveal that $\mathrm{N}$-glycosylation is a prerequisite to processing and membrane surface presentation of CDCP1. Increased sialylation and cell surface presentation of CDCP1 signals a transition between epithelial and tumor cell expression. These and other phenotypic changes in CDCP1 are faithfully conserved in extracellular vesicles derived from prostate cancer cells. We propose that dysregulated processing and expression of extracellular CDCP1 reflect the tumor microenvironment and a full structural characterizationis warranted to determine if circulating CDCP1 can provide a diagnostic/ prognostic tool for management of prostate cancer.

\section{MATERIALS AND METHODS}

\section{Patient samples}

Patient samples were collected from consented men following Institutional Review Board approved protocols. We stratified patients to D'Amico's risk categories; lowrisk (serum PSA $<10 \mathrm{ng} / \mathrm{mL}$, Gleason score $<7$, or clinical stage $<\mathrm{T} 2 \mathrm{~b}$ ), intermediate-risk (serum PSA between $10 \mathrm{ng}$ / $\mathrm{mL}$ and $20 \mathrm{ng} / \mathrm{mL}$, or Gleason score equal to 7, or clinical stage T2b) or high-risk (serum PSA $>20 \mathrm{ng} / \mathrm{mL}$, or Gleason score 8 to 10 , or clinical stage T2c-3a). Urine-EPS samples were collected as described [42]. Urine-EPS specimen pools comprised 10 samples (12 $\mathrm{ml}$ each) for a total volume of $120 \mathrm{ml}$. The clinicopathological characteristics of urineEPS samples are summarized in Table S1. Each pool was concentrated $200 \mathrm{X}$ by ultrafiltration.

\section{Cell culture and reagents}

Human prostate epithelial cell lines RWPE-1 and PZ-HPV-7, RWPE-1 sublines (WPE1-NB14, WPE1NB26 and WPE1-NB26/65), VCaP, LNCaP, DU145, 22RV1, HEK-293T, and MCF-7 were obtained from American Type Culture Collection. PC3 sublines PC3-N2 and PC3-ML2 [43] were provided by Mark E. Stearns (Drexel University, PA). The LNCaP sublines C4, C4-2 and C4-2B were developed by Leland W. Chung [44] and provided to us by ViroMed Labs. ARCaP cells and subclones were purchased from Novicure Biotechnology (Birmingham, AL). PacMetUT1 was developed by Dean A. Troyer [45]. Human prostate epithelial cell line HPrEC was purchased from Lifeline Cell Technology (Frederick, MD). CDCP1 antibodies used were: mouse monoclonal mAb 41-2 [8]provided by James P. Quigley (The Scripps Research Institute, CA); rabbit polyclonal CS4115 (Cell Signaling, Danvers, MA); mouse monoclonal mAB309137 and goat polyclonal AF2666 (R\&D Systems, Minneapolis, MN). Murine monoclonal anti- $\beta$-actin was from BD PharMingen (San Diego, CA) and rabbit polyclonal anti-GAPDH was from Santa Cruz Biotechnology (Santa Cruz, CA). IRDye 700 and IRDye 800 conjugated secondary antibodies were from Li-COR Bioscences (Lincoln, PA). Alexa Fluor 488 conjugated secondary antibodies were from Invitrogen (Carlsbad, CA). PNGase F, neuraminidase, and Endoglycosidase $\mathrm{H}$ were from New England Biolabs (Beverly, MA). High capacity streptavidin agarose resin and protein $\mathrm{A} / \mathrm{G}$ PLUS-agarose were from Thermo Scientific (Rockford, IL) and Santa Cruz Biotechnology (Santa Cruz, CA), respectively.

\section{Statement on authentication of cell lines}

Phenotypic verification was conducted upon receipt of cell lines and no genetic authentication was performed. All cultures were used at passage $2-8$. The morphology and expression of EMT markers (E-cadherin, N-cadherin, vimentin) was confirmed and cytokeratin 18 expression measured to verify epithelial origin. The expression of adhesion surface molecules (CDCP1, basigin, EGFR, Integrin) was determined.

\section{Immuno- and affinity blotting}

Whole cell lysates were collected in lysis buffer containing $1 \mathrm{x}$ protease inhibitor cocktail. Protein concentration was measured by the BCA protein assay (Thermo Scientific, Rockford, IL), separated by electrophoresis through $4-12 \%$ or $7.5 \%$ SDS-PAGE and then transferred to Immobilon-FL PDVF membranes (Millipore, Billerica, MA). Membranes were blocked in LiCor blocking buffer (LiCor, Lincoln, NE) diluted with PBS (1:1), then incubated with primary antibodies overnight at $4^{\circ} \mathrm{C}$. Following extensive washing, membranes were incubated 
with species-specific IRDye700 or 800-conjugated secondary antibodies $(1: 15,000)$ for $1 \mathrm{~h}$ at room temperature, and visualized with a LiCor Odyssey infrared imager (LiCor, Lincoln, NE). Consistent protein loading was determined by reprobing membranes with anti-actin or anti-GAPDH antibodies. To probe with lectins, the protein blot was blocked with protein-free blocking buffer (PFB, Thermo Scientific, Rockford, IL) at room temperature for $1 \mathrm{~h}$, and then probed overnight at $4^{\circ} \mathrm{C}$ with $1 \mu \mathrm{g} / \mathrm{ml}$ of biotinylated lectins (Vector Laboratories, Burlingame, $\mathrm{CA}$ ) in lectin-binding buffer (50 mM Tris, $\mathrm{pH} 7.5,0.15$ $\mathrm{M} \mathrm{NaCl}, 0.1 \mathrm{mM} \mathrm{CaCl}$ ). The filters were then washed with TBST (TBS with $0.05 \%$ Tween-20), incubated with IRDye 800-conjugated streptavidin in PFB for $1 \mathrm{~h}$ and then washed with TBST. The blots were imaged on the LiCor Odyssey system.

\section{Cell surface biotinylation}

$\mathrm{N} 2$ and ML2 cells were cultured in the absence or presence of tunicamycin $(1 \mu \mathrm{g} / \mathrm{ml})$ for $24 \mathrm{~h}$. The cells were then washed three times with ice-cold PBS. Cell surface proteins were subsequently biotinylated with $0.4 \mathrm{mg} / \mathrm{ml}$ Sulfo-NHS-LC-biotin (Pierce, Rockford, IL) in ice-cold PBS for $45 \mathrm{~min}$. Nonbiotinylated control cells were washed with ice-cold PBS. The reaction was quenched by washing cells three times with TBS (50 mM Tris, $150 \mathrm{Mm} \mathrm{NaCl}$, PH 7.4). Cells were then lysed in RIPA buffer $(0.5 \%$ sodium deoxycholate, $1 \%$ Nonidet-P 40, 0.1\% SDS, 2mM EDTA in Tris solution) containing protease inhibitors. The cell lysates were centrifuged at 14,000 $\mathrm{g}$ for $15 \mathrm{~min}$ to remove insoluble materials. The protein concentration was tested by BCA assay. To bind the biotinylated proteins, high capacity streptavidin-agarose beads (Thermo Scientific, Rockford, IL) were blocked with protein-free blocking buffer at $4^{\circ} \mathrm{C}$ overnight followed by TBS wash three times. $50 \mu \mathrm{l}$ pretreated beads were added to each $1 \mathrm{mg}$ supernatant lysate and incubated for overnight at $4{ }^{\circ} \mathrm{C}$. The beads were settled by centrifugation, and the supernatants (unbound fractions) were saved. The beads were then washed five times with RIPA buffer, and bound proteins were eluted by the addition of Laemmli buffer.

\section{Characterization of protein glycosylation}

For glycosidase digestion, $20 \mu \mathrm{g}$ cell lysates were mixed with 1,000 NEB units PNGase F, 1,000 NEB units Endo H, or 50 NEB units neuraminidase as indicated. For glycosylation inhibition assays, sub-confluent cells were washed twice with PBS and cultivated for $24 \mathrm{~h}$ in fresh culture media in the presence of $5 \mu \mathrm{g} / \mathrm{ml}$ tunicamycin or $1 \mu \mathrm{g} / \mathrm{ml}$ swainsonine. Cells were washed twice and lysed in M-PER buffer containing protease inhibitor. The lysates were centrifuged at $14,000 \mathrm{~g}$ for $15 \mathrm{~min}$ and supernatant collected.

\section{Assessment of overall sialylation}

N2 and ML2 cells were treated with 25 nMazidomodified sugars, tetraacetylated N-azidoacetyl-Dmannosamine $\left(\mathrm{AC}_{4} \mathrm{ManNAz}\right.$, Invitrogen, Carlsbad, $\left.\mathrm{CA}\right)$, and normal control sugars, N-acetyl-D-mannosamine (ManNAc) for $24 \mathrm{~h}$. Cells were lysed in M-PER lysis buffer with protease inhibitor. After CDCP1 was immunoprecipitated from the indicated amount of cell lystes, click reaction was performed with biotinylated alkyne capture reagent (0.1 mM alkyne biotin, $0.1 \mathrm{mM}$ Tris-triazoleamine catalyst, $1 \mathrm{mMCuSO}_{4}, 2 \mathrm{mM}$ sodium ascorbate) on eluted protein at room temperature for $1 \mathrm{~h}$. Unreactive reagents was removed by chloroform and methanol precipitation followed by solublizing protein in NuPAGE sample loading buffer (Invitrogen, Carlsbad, CA) and analyzed by Western blot with IRDye 800 conjugated streptavidin.

\section{Immunofluorescence staining}

Cells were seeded onto 6-well plates containing glass coverslips and cultured in growth medium to $80 \%$ confluence, washed with ice-cold PBS and fixed in $4 \%$ paraformaldehyde for $15 \mathrm{~min}$ at room temperature. For intracellular staining, the cells were permeabilized with $0.5 \%$ Triton X-100 in PBS for $10 \mathrm{~min}$ at room temperature. Fixed cells were washed twice with PBS and blocked with $3 \% \mathrm{BSA}$ in PBS for $1 \mathrm{~h}$ at room temperature. Cells were then incubated with primary antibody in blocking buffer overnight at $4^{\circ} \mathrm{C}$, washed three times and incubated with the appropriate conjugated secondary antibodies $(2 \mu \mathrm{g} / \mathrm{ml}$, Invitrogen, Carlsbad, CA) in the blocking buffer for $1 \mathrm{~h}$ at room temperature. Nuclei were counter-stained with TOPRO3, coverslips mounted to slides with VectorShield (Vector Labs, Burlingame, CA), and sealed with nail polish. Cells stained with normal goat or rabbit IgG were included as negative controls.

For tissue staining, Optimal Cutting Temperature reagent-embedded frozen $\mathrm{PCa}$ tissues were obtained from the Leroy T. Canoles Jr. Cancer Research Center biorepository. Cryosectioning was done on a Microm $\mathrm{HM} 505 \mathrm{E}$ cryostat at $-20^{\circ} \mathrm{C}$. A serial cryosection $(6 \mu \mathrm{m})$ was stained with $\mathrm{H} \& \mathrm{E}$ as a guide and analyzed by a pathologist to determine tissue morphology. Tissue sections were fixed in 4\% paraformaldehyde in PBS for 15 min, permeabilized with $0.5 \%$ Triton X-100 in PBS for 10 minutes, blocked with 3\% BSA in PBS for $1 \mathrm{~h}$ and incubated overnight at $4^{\circ} \mathrm{C}$ with primary antibody. Excess primary antibody was removed and the cells incubated with the appropriate conjugated secondary antibody in the blocking buffer for $1 \mathrm{~h}$ at room temperature. Nuclei were counter-stained with propidium iodide. An adjacent section stained with mouse normal IgG was used as the negative control. Imaging was done on an Olympus BX51 fluorescent microscope or a Zeiss LSM510 META confocal imaging system. 


\section{Preparation of extracellular vesicles}

Cells were grown to $80 \%$ confluence, rinsed and cultured in serum-free medium for $48 \mathrm{~h}$. Culture media was harvested and vesicles enriched by ultracentrifugation as described [46]. Briefly, the media were subjected to serial centrifugation to remove cells $(500 \mathrm{x} \mathrm{g}$ for $10 \mathrm{~min})$, dead cells (2,000x g for $20 \mathrm{~min})$, and cell debris $(20,000 \mathrm{x} \mathrm{g}$ for $30 \mathrm{~min})$. Vesicles were then collected by ultracentrifugation at $100,000 \mathrm{x}$ g for $90 \mathrm{~min}$ at $4^{\circ} \mathrm{C}$ using a SW28 rotor in an Optima X-100K ultracentrifuge (Beckman Coulter), washed with a large volume of icecold PBS, and concentrated by ultracentrifugation at $100,000 \mathrm{x}$ g for $90 \mathrm{~min}$ at $4^{\circ} \mathrm{C}$ in a SW40 rotor. Vesicle pellets were resuspended in PBS or lysis buffer and frozen at $-80^{\circ} \mathrm{C}$. The quantity of Vesicles was determined by Bradford protein assay (Thermo Scientific, Rockford, IL).

\section{Flow cytometry analysis}

For cell surface staining, subconfluent cells were harvested from the culture dishes by non-enzyme dissociation buffer (Invitrogen, Carlsbad, CA), washed with $2 \% \mathrm{FBS} / \mathrm{PBS}$, and incubated with primary antibody AF2666 $(5 \mu \mathrm{g} / \mathrm{ml})$ for $1 \mathrm{~h}$ at $4^{\circ} \mathrm{C}$. Cells were washed twice and incubated with Alexa Fluor 488-conjugated donkey anti-goat antibody $(2 \mu \mathrm{g} / \mathrm{ml}$, Invitrogen, Carlsbad, CA) for $30 \mathrm{~min}$ at $4{ }^{\circ} \mathrm{C}$. Cells were then treated with propidium iodide $(1 \mu \mathrm{g} / \mathrm{ml})$ in $500 \mu \mathrm{l} 2 \% \mathrm{FBS} / \mathrm{PBS}$ for $20 \mathrm{~min}$ at $4^{\circ} \mathrm{C}$. Cells stained with goat normal $\operatorname{IgG}$ were used as the isotype controls. Flow cytometry of isolated extracellular vesicles was performed as described [46]. Briefly, vesiclecoated beads were prepared by incubating purified extracellular vesicles ( $5 \mu \mathrm{g}$ protein) with $4 \mu \mathrm{m}$ aldehyde/ sulfate latex beads ( $5 \mu \mathrm{l}$ of $4 \% \mathrm{w} / \mathrm{v}$ suspension, Invitrogen, Carlsbad, CA) in PBS for overnight at $4^{\circ} \mathrm{C}$ under constant agitation. The reaction was stopped by addition of $1 \mathrm{M}$ glycine, followed by three washes in FACS buffer (2\% FBS/PBS). Vesicle-coated beads were then incubated with goat polyclonal anti-CDCP1 AF2666 antibody $(5 \mu \mathrm{g} / \mathrm{ml})$ or rabbit polyclonal CS4115 $(5 \mu \mathrm{g} / \mathrm{ml})$, anti-CD9 $(5 \mu \mathrm{g} /$ $\mathrm{ml}$, clone M-L13, BD Biosciences, San Jose, CA) and antiCD63 $(5 \mu \mathrm{g} / \mathrm{ml}$, clone H5C6, BD Biosciences, San Jose, CA) or isotype control ( $5 \mu \mathrm{g} / \mathrm{ml}$, Santa Cruz Biotechnology, Santa Cruz, CA) followed by Alex Fluor 488-conjugated secondary antibodies $(4 \mu \mathrm{g} / \mathrm{ml}$, Invitrogen, Carlsbad, CA). Flow cytometry was performed on a FACSAria instrument (BD Biosciences), and data were analyzed using Flowjo software (Tree Star Inc).

\section{Immuno-mass spectrometry analysis of circulating CDCP1}

$1.2 \mathrm{mg}$ total protein of concentrated Urine-EPS pools was pre-cleared with goat $\operatorname{IgG}$, incubated with $5 \mu \mathrm{g}$ goat anti-CDCP1 (AF2666) and immunoprecipitated.
Bound proteins were eluted and subjected to SDS-PAGE. Gel regions were excised, destained and washed with a series of three washing buffers $(50 \mathrm{mM}$ ammonium bicarbonate, $50 \%$ acetonitrile and $80 \%$ acetonitrile). Proteins were reduced, alkylated and digested as previously described [47]. Dried samples were dissolved with $20 \mu \mathrm{l}$ of $0.1 \%$ formic acid/water. $2 \mu \mathrm{l}$ of each sample was analyzed by LC/ESI-MS/MS using a Q-Exactive (Thermo Fisher Scientific, Bremen, Germany) mass spectrometer with an Easy NanoLC-1000 system using data dependent acquisition with dynamic exclusion $(\mathrm{DE}=1)$. MS acquisition parameters used have been described elsewhere [48]. Pinpoint (version 1.1, Thermo Scientific) was employed to determine optimal peptide targets. Retention time and accurate $\mathrm{m} / \mathrm{z}$ for each targeted peptide was used in the acquisition method for scheduled MS/MS. Six of the identified peptides were selected and exported as a retention time-dependent inclusion list to build the acquisition method. Quantitation analysis was performed in triplicate using an automated fashion using a $5 \mathrm{ppm}$ window for extracted ion chromatograms.

\section{Construction and immunohistochemical analysis of tissue microarray}

Formalin fixed paraffin embedded tissue blocks were obtained from men undergoing radical prostatectomy between 1990 and 2006 at Sentara Norfolk General Hospital (Norfolk, VA) under an IRB-approved protocol for development of Retrospective Prostate Tissue Microarrys. The clinicopathological characteristics of the patients are summarized in table 1 . Three TMAs consisting of 100 cases of primary prostate cancer with matched benign tissues were generated. After evaluation by a pathologist, three representative cores $(1.0 \mathrm{~mm}$ in diameter) and one core from matched normal tissue were taken from a randomly selected tumor block reflecting the Gleason grade of the pathological diagnosis from each patient and arranged in tissue microarray blocks using TMA Arrayer (Pathology Devices, Westminster, MD). For internal controls, each TMA block contained normal prostate, kidney, liver, tonsil and colon tissue. $4 \mu \mathrm{m}$ sections from TMA blocks were deparaffinized and rehydrated in xylene and graded ethanol baths. The antigen was retrieved in $10 \mathrm{mM}$ sodium citrate ( $\mathrm{pH}$ 6.0) in boiling water for $20 \mathrm{~min}$. Slides were then blocked with $10 \%$ normal horse serum in $1 \% \mathrm{BSA} /$ PBS at room temperature for $1 \mathrm{~h}$ and incubated overnight at $4^{\circ} \mathrm{C}$ with primary mouse anti-CDCP1 antibody mAb309137 $(0.5 \mu \mathrm{g} / \mathrm{ml})$ or mouse isotype antibody (negative control). The next day slides were blocked with $3 \% \mathrm{H}_{2} \mathrm{O}_{2}$ and avidin/ biotin blocking kit (Vector Lab). Secondary staining was performed with biotinylated horse anti-mouse antibodies $(50 \mu \mathrm{g} / \mathrm{ml}$, Vector Lab) and visualized with Vectastain $\mathrm{ABC}$ kit (Vector Lab) and 3, 3'-diaminobenzidine (DAB)- $\mathrm{H}_{2} \mathrm{O}_{2}$ Substrate (BD Biosciences). Slides were counterstained with haematoxylin, dehydrated with ethanol/xylene and 
Table 1: Clinicopathological Features of Patient Samples Used to Make EPS-urine Pools

\begin{tabular}{|c|c|c|c|c|c|c|}
\hline Sample \# & StageT & GS & PSA (ng/ml) & Cores & Pos & $\%$ Pos \\
\hline \multicolumn{7}{|c|}{ Low-risk group } \\
\hline 1 & T1c & $3+3$ & 3.37 & 12 & 4 & 33.33 \\
\hline 2 & T1c & $3+3$ & 4.35 & 12 & 2 & 16.67 \\
\hline 3 & T1c & $3+3$ & 7.29 & 12 & 1 & 8.33 \\
\hline 4 & T1c & $3+3$ & 4.00 & 12 & 4 & 33.33 \\
\hline 5 & T1c & $3+3$ & 5.10 & 12 & 2 & 16.67 \\
\hline 6 & T1c & $3+3$ & 3.40 & 12 & 6 & 50.00 \\
\hline 7 & $\mathrm{~T} 1 \mathrm{c}$ & $3+3$ & 3.90 & 12 & 3 & 25.00 \\
\hline 8 & T1c & $3+3$ & 4.80 & 12 & 5 & 41.67 \\
\hline 9 & T1c & $3+3$ & 4.08 & 12 & 1 & 8.33 \\
\hline 10 & $\mathrm{~T} 1 \mathrm{c}$ & $3+3$ & 4.00 & 12 & 2 & 16.67 \\
\hline \multicolumn{7}{|c|}{ Intermediate-risk group } \\
\hline 1 & $\mathrm{~T} 1 \mathrm{c}$ & $4+3$ & 5.30 & 12 & 5 & 41.67 \\
\hline 2 & $\mathrm{~T} 2 \mathrm{a}$ & $4+3$ & 3.58 & 12 & 5 & 41.67 \\
\hline 3 & T1c & $4+3$ & 15.80 & 12 & 8 & 66.67 \\
\hline 4 & T1c & $4+3$ & 5.38 & 12 & 6 & 50.00 \\
\hline 5 & T1c & $4+3$ & 8.10 & 12 & 4 & 33.33 \\
\hline 6 & T1c & $4+3$ & 5.10 & 12 & 2 & 16.67 \\
\hline 7 & $\mathrm{~T} 2$ & $4+3$ & 8.41 & 14 & 8 & 57.14 \\
\hline 8 & $\mathrm{~T} 2 \mathrm{~b}$ & $4+3$ & 4.30 & 12 & 12 & 100.00 \\
\hline 9 & $\mathrm{~T} 1 \mathrm{c}$ & $4+3$ & 10.90 & 12 & 5 & 41.67 \\
\hline 10 & T1c & $4+3$ & 4.70 & 12 & 3 & 25.00 \\
\hline \multicolumn{7}{|c|}{ High-risk group } \\
\hline 1 & $\mathrm{~T} 2 \mathrm{a}$ & $5+4$ & 0.53 & 12 & 11 & 91.67 \\
\hline 2 & $\mathrm{~T} 2 \mathrm{a}$ & $4+4$ & 32.49 & 13 & 5 & 38.46 \\
\hline 3 & T1c & $5+4$ & 80.90 & 12 & 6 & 50.00 \\
\hline 4 & T1c & $4+4$ & 9.05 & 12 & 10 & 83.33 \\
\hline 5 & $\mathrm{~T} 2 \mathrm{c}$ & $4+5$ & 27.90 & 12 & 9 & 75.00 \\
\hline 6 & $\mathrm{~T} 2 \mathrm{a}$ & $4+5$ & 9.38 & 12 & 6 & 50.00 \\
\hline 7 & Unkown & $4+4$ & 52.99 & & & \\
\hline 8 & $\mathrm{~T} 2 \mathrm{a}$ & $4+5$ & 8.30 & 12 & 12 & 100.00 \\
\hline 9 & T1c & $4+4$ & 6.28 & 12 & 3 & 25.00 \\
\hline 10 & $\mathrm{~T} 2 \mathrm{c}$ & $4+5$ & 2.70 & 15 & 5 & 41.67 \\
\hline
\end{tabular}

Abbreviations: PSA, prostate-specific antigen; Pos, positive cores; GS, Gleason score.

mounted. Slides were viewed and imaged under bright-field mode on a Zeiss AxioImager Z1 microscope fitted with an AxioCamMRc digital camera (Carl Zeiss, Thornwood, NY). Semi-quantitative assessment of immunoreactivity was performed by a pathologist in a blinded fashion. The staining intensity was graded as weak $(1+)$, moderate $(2+)$ or strong $(3+)$. The total IHC score was calculated by multiplying the percentage of positive cells $(0-100 \%)$ and staining intensity $(1+$ to $3+)$ so that CDCP1 IHC score ranged from $0-300$.

\section{ACKNOWLEDGMENTS AND FUNDINGS}

We thank members of the Leroy T. Canoles Jr. Cancer Research Center at Eastern Virginia Medical School; Mary Ann Clements and Brian Main for clinical samples and data retrieval, Arjun Poddar for statistical analysis. We also thank Siqi Guo and Yu Jing of the Frank Reidy Research Center for Bioelectrics (FRRCBE) at Old Dominion University for their assistance with flow cytometry analysis. 


\section{CONFLICTS OF INTEREST}

No potential conflicts of interest.

\section{REFERENCES}

1. Moremen KW, Tiemeyer M, Nairn AV. Vertebrate protein glycosylation: diversity, synthesis and function. Nat Rev Mol Cell Biol. 2012; 13:448-62.

2. Hakomori S. Glycosylation defining cancer malignancy: new wine in an old bottle. Proc Natl Acad Sci USA. 2002; 99:10231-3.

3. Drake PM, Cho W, Li B, Prakobphol A, Johansen E, Anderson NL, et al. Sweetening the pot: adding glycosylation to the biomarker discovery equation. Clin Chem. 2010; 56:223-36.

4. Lange T, Ullrich S, Müller I, Nentwich MF, Stübke K, Feldhaus $\mathrm{S}$, et al. Human prostate cancer in a clinically relevant xenograft mouse model: identification of $\beta(1,6)$-branched oligosaccharides as a marker of tumor progression. Clin Cancer Res. 2012; 18:1364-73.

5. Liu Y-C, Yen H-Y, Chen C-Y, Chen C-H, Cheng P-F, Juan Y-H, et al. Sialylation and fucosylation of epidermal growth factor receptor suppress its dimerization and activation in lung cancer cells. Proc Natl Acad Sci USA. 2011; 108:11332-7.

6. Lange T, Kupfernagel M, Wicklein D, Gebauer F, Maar H, Brügge K, et al. Aberrant presentation of HPA-reactive carbohydrates implies Selectin-independent metastasis formation in human prostate cancer. Clin Cancer Res. 2014; 20:1791-802.

7. Yang L, Nyalwidhe JO, Guo S, Drake RR, Semmes OJ. Targeted identification of metastasis-associated cell-surface sialoglycoproteins in prostate cancer. Mol Cell Proteomics. 2011; 10:M110.007294.

8. Hooper JD, Zijlstra A, Aimes RT, Liang H, Claassen GF, Tarin D, et al. Subtractive immunization using highly metastatic human tumor cells identifies SIMA135/CDCP1, a $135 \mathrm{kDa}$ cell surface phosphorylated glycoprotein antigen. Oncogene. 2003; 22:1783-94.

9. Brown TA, Yang TM, Zaitsevskaia T, Xia Y, Dunn CA, Sigle RO, et al. Adhesion or plasmin regulates tyrosine phosphorylation of a novel membrane glycoprotein $\mathrm{p} 80 /$ gp140/CUB domain-containing protein 1 in epithelia. J Biol Chem. 2004; 279:14772-83.

10. Bhatt AS, Erdjument-Bromage H, Tempst P, Craik CS, Moasser MM. Adhesion signaling by a novel mitotic substrate of src kinases. Oncogene. 2005; 24: 5333-43.

11. Wortmann A, He Y, Deryugina EI, Quigley JP, Hooper JD. The cell surface glycoprotein CDCP1 in cancer-insights, opportunities, and challenges. IUBMB Life. 2009; 61:723-30.

12. Bühring H-J, Kuçi S, Conze T, Rathke G, Bartolović K, Grünebach F, et al. CDCP1 identifies a broad spectrum of normal and malignant stem/progenitor cell subsets of hematopoietic and nonhematopoietic origin. Stem Cells. 2004; 22:334-43.

13. Conze T, Lammers R, Kuçi S, Scherl-Mostageer M, Schweifer N, Kanz L, et al. CDCP1 is a novel marker for hematopoietic stem cells. Ann N Y Acad Sci. 2003; 996:222-6.

14. Ikeda J-I, Morii E, Kimura H, Tomita Y, Takakuwa T, Hasegawa J-I, et al. Epigenetic regulation of the expression of the novel stem cell marker CDCP1 in cancer cells. J Pathol. 2006; 210:75-84.

15. Scherl-Mostageer M, Sommergruber W, Abseher R, Hauptmann R, Ambros P, Schweifer N. Identification of a novel gene, CDCP1, overexpressed in human colorectal cancer. Oncogene. 2001; 20:4402-8.

16. Awakura Y, Nakamura E, Takahashi T, Kotani H, Mikami Y, Kadowaki T, et al. Microarray-based identification of CUBdomain containing protein 1 as a potential prognostic marker in conventional renal cell carcinoma. J Cancer Res Clin Oncol. 2008; 134:1363-9.

17. Miyazawa $\mathrm{Y}$, Uekita $\mathrm{T}$, Ito $\mathrm{Y}$, Seiki M, Yamaguchi H, Sakai R. CDCP1 regulates the function of MT1-MMP and invadopodia-mediated invasion of cancer cells. Mol Cancer Res. 2013; 11:628-37.

18. Ikeda J-I, Oda T, Inoue M, Uekita T, Sakai R, Okumura M, et al. Expression of CUB domain containing protein (CDCP1) is correlated with prognosis and survival of patients with adenocarcinoma of lung. Cancer Sci. 2009; 100:429-33.

19. Uekita T, Jia L, Narisawa-Saito M, Yokota J, Kiyono T, Sakai R. CUB domain-containing protein 1 is a novel regulator of anoikis resistance in lung adenocarcinoma. Mol Cell Biol. 2007; 27:7649-60.

20. Uekita T, Tanaka M, Takigahira M, Miyazawa Y, Nakanishi Y, Kanai Y, et al. CUB-domain-containing protein 1 regulates peritoneal dissemination of gastric scirrhous carcinoma. Am J Pathol. 2008; 172:1729-39.

21. Miyazawa Y, Uekita T, Hiraoka N, Fujii S, Kosuge T, Kanai $Y$, et al. CUB domain-containing protein 1, a prognostic factor for human pancreatic cancers, promotes cell migration and extracellular matrix degradation. Cancer Res. 2010; 70:5136-46.

22. Spassov DS, Baehner FL, Wong CH, McDonough S, Moasser MM. The transmembrane src substrate Trask is an epithelial protein that signals during anchorage deprivation. Am J Pathol. 2009; 174:1756-65.

23. Sandvig K, Llorente A. Proteomic analysis of microvesicles released by the human prostate cancer cell line PC-3. Mol Cell Proteomics. 2012;11:M111.012914-4.

24. Siva AC, Wild MA, Kirkland RE, Nolan MJ, Lin B, Maruyama $\mathrm{T}$, et al. Targeting CUB domain-containing protein 1 with a monoclonal antibody inhibits metastasis in a prostate cancer model. Cancer Res. 2008; 68:3759-66.

25. He Y, Wortmann A, Burke LJ, Reid JC, Adams MN, AbdulJabbar I, et al. Proteolysis-induced N-terminal ectodomain shedding of the integral membrane glycoprotein CUB 
domain-containing protein 1 (CDCP1) is accompanied by tyrosine phosphorylation of its C-terminal domain and recruitment of Src and PKCdelta. J Biol Chem. 2010; 285:26162-73.

26. Wong CH, Baehner FL, Spassov DS, Ahuja D, Wang D, Hann B, et al. Phosphorylation of the SRC epithelial substrate Trask is tightly regulated in normal epithelia but widespread in many human epithelial cancers. Clin Cancer Res. 2009; 15:2311-22.

27. Xia Y, Gil SG, Carter WG. Anchorage mediated by integrin alpha6beta4 to laminin 5 (epiligrin) regulates tyrosine phosphorylation of a membrane-associated $80-\mathrm{kD}$ protein. The Journal of Cell Biology. 1996; 132:727-40.

28. Uekita T, Fujii S, Miyazawa Y, Iwakawa R, NarisawaSaito M, Nakashima K, et al. Oncogenic Ras/ERK Signaling Activates CDCP1 to Promote Tumor Invasion and Metastasis. Mol Cancer Res. 2014; 12:1449-59.

29. Uekita T, Fujii S, Miyazawa Y, Hashiguchi A, Abe H, Sakamoto M, et al. Suppression of autophagy by CUB domain-containing protein 1 signaling is essential for anchorage-independent survival of lung cancer cells. Cancer Sci. 2013; 104:865-70.

30. Casar B, He Y, Iconomou M, Hooper JD, Quigley JP, Deryugina EI. Blocking of CDCP1 cleavage in vivo prevents Akt-dependent survival and inhibits metastatic colonization through PARP1-mediated apoptosis of cancer cells. Oncogene. 2012; 31:3924-38.

31. Casar B, Rimann I, Kato H, Shattil SJ, Quigley JP, Deryugina EI. In vivo cleaved CDCP1 promotes early tumor dissemination via complexing with activated $\beta 1$ integrin and induction of FAK/PI3K/Akt motility signaling. Oncogene. 2014; 33:255-68.

32. Liu H, Ong S-E, Badu-Nkansah K, Schindler J, White FM, Hynes RO. CUB-domain-containing protein 1 (CDCP1) activates Src to promote melanoma metastasis. Proc Natl Acad Sci USA. 2011; 108:1379-84.

33. Athauda G, Giubellino A, Coleman JA, Horak C, Steeg PS, Lee M-J, et al. c-Met ectodomain shedding rate correlates with malignant potential. Clin Cancer Res. 2006; 12:4154-62.

34. Stamenkovic I, Yu Q. Shedding light on proteolytic cleavage of CD44: the responsible sheddase and functional significance of shedding. J Invest Dermatol. 2009; 129:1321-4.

35. Baron AT, Cora EM, Lafky JM, Boardman CH, Buenafe $\mathrm{MC}$, Rademaker A, et al. Soluble epidermal growth factor receptor (sEGFR/sErbB1) as a potential risk, screening, and diagnostic serum biomarker of epithelial ovarian cancer. Cancer Epidemiol Biomarkers Prev. 2003; 12:103-13.

36. Spassov DS, Wong $\mathrm{CH}$, Harris $\mathrm{G}$, McDonough $\mathrm{S}$, Phojanakong P, Wang D, et al. A tumor-suppressing function in the epithelial adhesion protein Trask. Oncogene. 2012; 31:419-31.
37. Spassov DS, Wong CH, Wong SY, Reiter JF, Moasser MM. Trask loss enhances tumorigenic growth by liberating integrin signaling and growth factor receptor cross-talk in unanchored cells. Cancer Res. 2013; 73:1168-79.

38. Adams MN, Harrington BS, He Y, Davies CM, Wallace SJ, Chetty NP, et al. EGF inhibits constitutive internalization and palmitoylation-dependent degradation of membranespanning procancer CDCP1 promoting its availability on the cell surface. Oncogene. 2014; 34:1375-83.

39. Lin C-Y, Chen H-J, Huang C-C, Lai L-C, Lu T-P, Tseng G-C, et al. ADAM9 promotes lung cancer metastases to brain by a plasminogen activator-based pathway. Cancer Research 2014; 74:5229-43.

40. Chou C-T, Li Y-J, Chang C-C, Yang C-N, Li P-S, Jeng Y-M, et al. Prognostic significance of CDCP1 expression in colorectal cancer and effect of its inhibition on invasion and migration. Ann Surg Oncol. 2015; 1:1-9.

41. Sawada G, Takahashi Y, Niida A, Shimamura T, Kurashige J, Matsumura T, et al. Loss of CDCP1 Expression Promotes Invasiveness and Poor Prognosis in Esophageal Squamous Cell Carcinoma. Ann Surg Oncol. 2014; Suppl 4:s640-7.

42. Drake RR, White KY, Fuller TW, Igwe E, Clements MA, Nyalwidhe JO, et al. Clinical collection and protein properties of expressed prostatic secretions as a source for biomarkers of prostatic disease. J Proteomics. 2009; 72:907-17.

43. Wang M, Stearns ME. Isolation and characterization of PC-3 human prostatic tumor sublines which preferentially metastasize to select organs in S.C.I.D. mice. Differentiation. 1991; 48:115-25.

44. Wu HC, Hsieh JT, Gleave ME, Brown NM, Pathak S, Chung LW. Derivation of androgen-independent human LNCaP prostatic cancer cell sublines: role of bone stromal cells. Int J Cancer. 1994; 57:406-12.

45. Troyer DA, Tang Y, Bedolla R, Adhvaryu SG, Thompson IM, Abboud-Werner $\mathrm{S}$, et al. Characterization of PacMetUT1, a recently isolated human prostate cancer cell line. Prostate. 2008; 68:883-92.

46. Théry C, Amigorena S, Raposo G, Clayton A. Isolation and characterization of exosomes from cell culture supernatants and biological fluids. Curr Protoc Cell Biol. Hoboken, NJ, USA: John Wiley \& Sons, Inc; 2006; Chapter 3: Unit3.22-3.22.29.

47. Borner GHH, Fielding AB. Using in-gel digestion and an Orbitrap mass spectrometer to analyze the proteome of clathrin-coated vesicles. Cold Spring Harb Protoc. 2014; 2014:1188-91.

48. Michalski A, Damoc E, Hauschild J-P, Lange O, Wieghaus A, Makarov A, et al. Mass spectrometry-based proteomics using Q Exactive, a high-performance benchtop quadrupole Orbitrap mass spectrometer. Mol Cell Proteomics. 2011; 10:M111.011015-5. 